\title{
Hipoplasia do músculo grande dorsal: relato de caso
}

\section{Latissimus dorsi muscle hypoplasy: case report}

\author{
Tatiana Nunes Ferreira ${ }^{1}$ \\ Walter Soares Pinto ${ }^{2}$ \\ Douglas Haddad Filho ${ }^{3}$
}

Trabalho realizado na Universidade de Santo Amaro (UNISA), São Paulo, SP, Brasil.

Artigo submetido pelo SGP (Sistema de Gestão de Publicações) da RBCP.

Artigo recebido: 7/6/2009 Artigo aceito: 18/9/2009

\begin{abstract}
RESUMO
Introdução: $\mathrm{O}$ músculo grande dorsal é largo, um retalho muscular muito versátil e bem vascularizado. Devido a sua confiabilidade, é frequentemente usado para reconstrução de mama após mastectomia. Ele pode também ser usado na reconstrução de cabeça, pescoço e tórax, pediculado ou como retalho livre. Relato do caso: Os autores relatam o caso de uma paciente no pós-operatório de 8 anos de uma mastectomia esquerda e reconstrução imediata com implante mamário de silicone, que após radioterapia evoluiu com radiodermite e extrusão do implante. Foi programada, então, reconstrução com o músculo grande dorsal e, durante a cirurgia, foi identificado um músculo hipoplásico, que inviabilizou a sua utilização para o procedimento proposto.
\end{abstract}

Descritores: Mastectomia. Retalhos cirúrgicos. Músculo esquelético/transplante.

\section{SUMMARY}

Introduction: The latissimus dorsi muscle is a wide and well vascularized flap with great versatility. Its reliance brings a very good option of reconstruction following mastectomy. It also can be used for head, neck and chest reconstruction both a pedicled or as a free flap. Case report: The authors present a case of a patient who was submitted to a left mastectomy 8 years ago and had immediate reconstruction with silicone implant that extruded due to radiotherapy. The initial surgery proposal was to perform a regular latissimus dorsi flap to rebuild the breast but during the procedure it was found a hypoplasic muscle that resulted in an impracticable proper reconstruction.

Descriptors: Mastectomy. Surgical flaps. Muscle, skeletal/transplantation.

\section{INTRODUÇÃO}

A utilização do músculo grande dorsal foi descrita, em 1906, por Iginio Tansini para fechamento da área cutânea proveniente de mastectomia ${ }^{1}$. Contemporâneo de Tansini, Halsted criticava a utilização dos retalhos músculo-cutâneos, preferindo as enxertias de pele para o fechamento da região torácica anterior, após mastectomia. Este fato, juntamente com as dificuldades de comunicação da época, fez com que os retalhos miocutâneos não fossem utilizados, retornando somente décadas depois. Assim, em 1976, Olivari reutilizou o músculo grande dorsal para o fechamento da parede anterior do tórax, pós-ressecção de câncer de mama.

Atualmente, esse músculoéutilizado com muita versatilidade, podendo ser aplicado em reconstrução de cabeça e pescoço, de tórax anterior e posterior, de mama e também como retalho livre.

\section{Anatomia}

O músculo grande dorsal é largo, medindo cerca de 20 x $40 \mathrm{~cm}$, origina-se na $6^{\mathrm{a}} \mathrm{e} 7^{\mathrm{a}}$ vértebra torácica, fáscia toracolombar e, inferiormente, na crista ilíaca. Sua inserção é no sulco intertubercular do úmero.

A inervação é feita pelo nervo toracodorsal (C6-8), o qual penetra no músculo adjacente ao pedículo vascular, na axila posterior.

Seu pedículo dominante é a artéria toracodorsal, ramo da artéria subescapular. $O$ pedículo segmentar secundário se faz, em sua porção lateral, por perfurantes provenientes da artéria intercostal posterior e, em sua porção medial, por ramos da artéria lombar, o que o classifica como um retalho muscular do tipo $\mathrm{V}$, segundo a classificação de Mathes e $\mathrm{Nahai}^{2,3}$.

\footnotetext{
1. Médica residente de Cirurgia Plástica.

2. Cirurgião Plástico; Professor titular e chefe da Disciplina de Cirurgia Plástica da Faculdade de Medicina da Universidade de Santo Amaro (UNISA).

3. Cirurgião Plástico; Professor assistente de Cirurgia Plástica da Faculdade de Medicina da UNISA.
} 
As principais funções do músculo grande dorsal são adução e rotação medial do braço. Movimenta também o ombro, inferior e posteriormente ${ }^{1}$.

\section{RELATO DE CASO}

I.M.G, 55 anos, natural e procedente de São Paulo, há 8 anos foi submetida a mastectomia radical com esvaziamento linfonodal esquerdo, por carcinoma ductal infiltrativo, e reconstrução imediata com implante mamário de silicone, volume de $260 \mathrm{ml}$, em plano submuscular.

Após seções de radioterapia, a paciente evoluiu com radiodermite e extrusão do implante mamário. Após 7 anos, ela procurou nosso serviço desejando reconstruir novamente a mama.

Foi discutido com a paciente e optado pela reconstrução com músculo grande dorsal e implante de silicone, uma vez

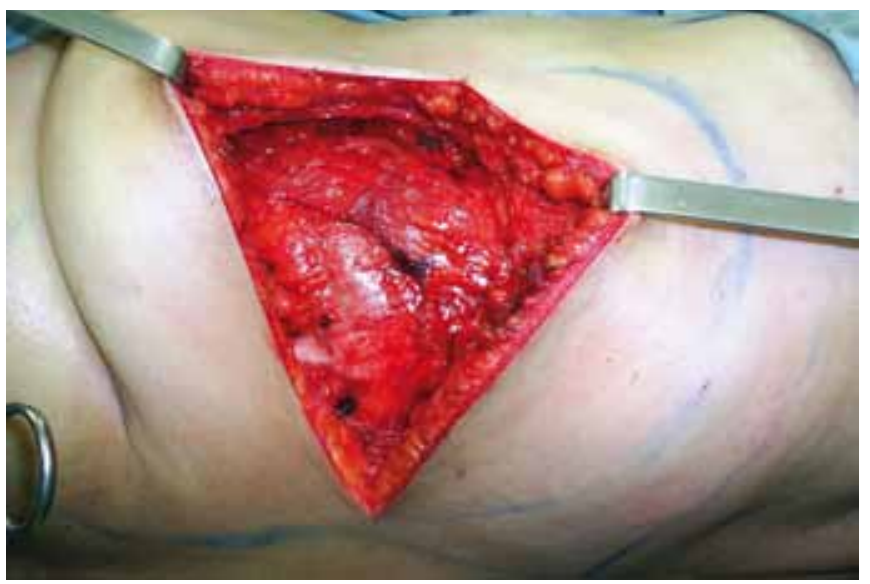

Figura 1 - Observa-se o gradeado costal esquerdo e a fita muscular acima deste.

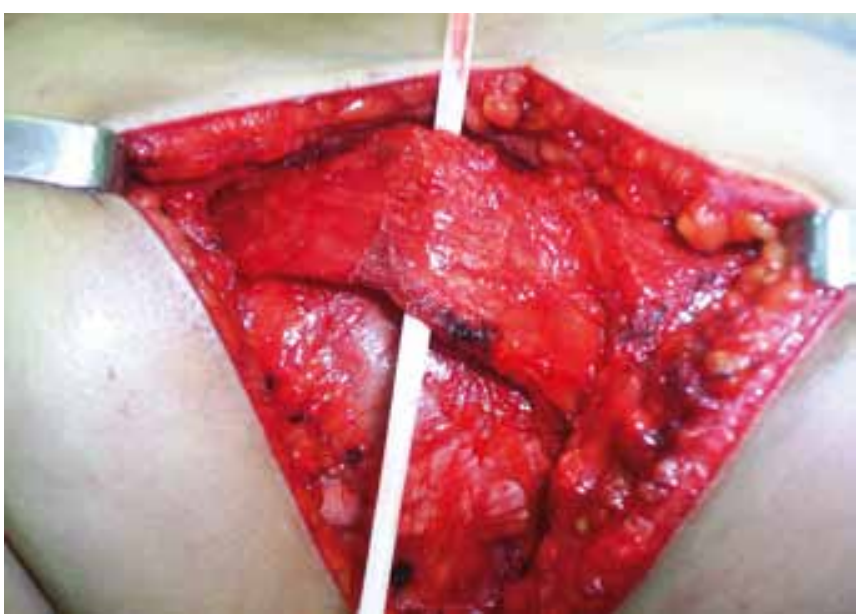

Figura 2 - Detalhe da largura da fita muscular.

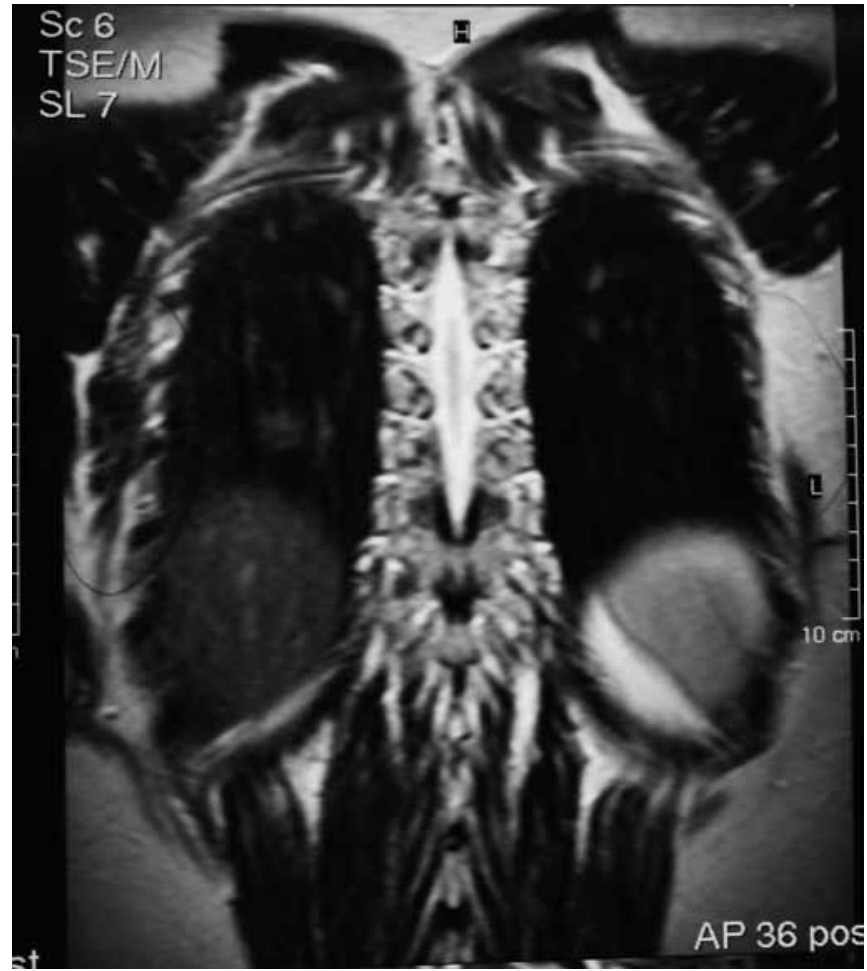

Figura 3 - Ressonância magnética demonstrando ausência da musculatura dorsal.

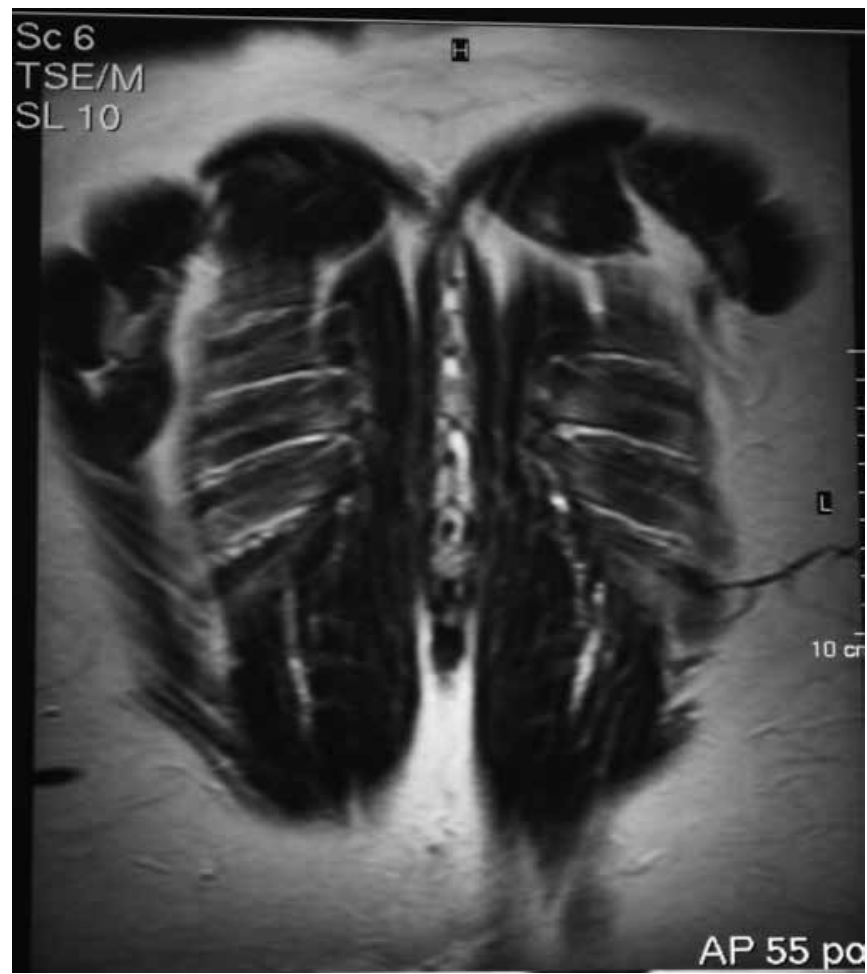

Figura 4 - Ressonância magnética demonstrando gradeado costal e ausência da musculatura dorsal. 
que essa havia sido submetida a diversas cirurgias abdominais anteriores, inviabilizando a utilização do retalho abdominal.

Para tal procedimento, foram realizados os exames de rotina, o que incluía o Doppler de artéria toracodorsal, a qual se apresentava íntegra e com bom fluxo.

No intra-operatório, foi evidenciada uma fita muscular na topografia do músculo grande dorsal à esquerda, que se estendia da crista ilíaca até a região escapular, com aproximadamente $5 \mathrm{~cm}$ de largura (Figuras $1 \mathrm{e} 2$ ). Além dessa alteração anatômica específica, toda a musculatura dorsal esquerda estava ausente.

Assim, procedemos à documentação fotográfica e ao fechamento por planos da incisão.

No pós-operatório, foi realizado uma ressonância magnética, cujo resultado foi assimetria volumétrica dos ventres musculares dos músculos trapézios, grande dorsais e eretores da espinha, sendo estes menores à esquerda, porém com trofismo conservado bilateralmente (Figuras 3 e 4 ).

\section{DISCUSSÃO}

A hipoplasia do músculo grande dorsal é muito rara, assim como a dos músculos trapézios e eretores da espinha. Após extensa pesquisa bibliográfica, encontramos apenas um caso semelhante ao apresentado ${ }^{4}$ e outro com ausência da sua porção inferior ${ }^{5}$.
Em alguns livros de anatomia pesquisados, as variações anatômicas são referentes à variação de inserção, fascículos acessórios e união completa com outros músculos ${ }^{6}$.

No caso relatado nesse artigo, o músculo se estendia da crista ilíaca até a escápula e tinha apenas $5 \mathrm{~cm}$ de largura, não tendo conexão lateral até a linha axilar posterior e, anteriormente, até o úmero, como é o padrão descrito anatomicamente.

Nós acreditamos que o número de casos descritos na literatura possa estar subestimado pela dificuldade diagnóstica, uma vez que as manifestações clínicas são inexistentes e o diagnóstico somente é feito por exame de imagem ou por exploração cirúrgica.

\section{REFERÊNCIAS}

1. Mélega JM. Cirurgia plástica fundamentos e arte: cirurgia reparadora de troncos e membros. Rio de Janeiro:Medsi;2004.

2. Mathes SJ, Nahai F. Reconstructive surgery: principles, anatomy and technique. vol. I. New York:Churchill Livingstone;1997.

3. Moore KL, Dalley AF. Anatomia orientada para a clínica. Rio de Janeiro:Guanabara Koogan;2007.

4. Cochran JH Jr, Pauly TJ, Edstrom LE, Dibbell DG. Hypoplasia of the latissimus dorsi muscle complicating breast reconstruction in Poland's syndrome. Ann Plast Surg. 1981;6(5):402-4.

5. Furnas DW, Furnas H. Absence of the lower part of the latissimus dorsi muscle: an important anatomical variation. Ann Plast Surg. 1983;10(1):70-1.

6. Chez L Homme, Testiet L. Les anomalies musculares. Paris:G Massan Editeurs;1884. p.106-17.

\section{Correspondência para:}

